\title{
"Our people has got to come to terms with that": changing perceptions of the digital rectal examination as a barrier to prostate cancer diagnosis in African-Caribbean men
}

\author{
Sarah Seymour-Smith* | David Brown | Georgina Cosma | Nicholas Shopland I \\ Steven Battersby I Andy Burton
}

Nottingham Trent University, Nottingham, UK Correspondence

Sarah Seymour-Smith, Nottingham Trent University, Burton Street, Nottingham, NG1 4BU, UK.

Email: sarah.seymour-smith@ntu.ac.uk

\begin{abstract}
Objective African-Caribbean men in the United Kingdom in comparison with other ethnicities have the highest incidence rate of prostate cancer. Psychosocial aspects related to screening and presentation impact on men's behavior, with previous studies indicating a range of barriers. This study explores one such barrier, the digital rectal examination (DRE), due to its prominence within UK African-Caribbean men's accounts.
\end{abstract}

Methods African-Caribbean men with prostate cancer $(n=10)$ and without cancer $(n=10)$ were interviewed about their perceptions of DRE. A synthetic discursive approach was employed to analyze the data.

Results Findingsillustrate that an interpretative repertoire of homophobia in relation to the DRE is constructed as having an impact upon African-Caribbean men's uptake of prostate cancer screening. However, the discursive focus on footing and accountability highlight deviations from this repertoire that are built up as pragmatic and orient to changing perceptions within the community.

Conclusions Health promotion interventions need to address the fear of homophobia and are best designed in collaboration with the community.

\section{KEYWORDS}

African-Caribbean, barrier, cancer, oncology, prostate

\section{1 | BACKGROUND}

Prostate cancer (PC) affects more than 40000 men in the United Kingdom each year, of whom around 10800 die from the disease per year, making this type of cancer the second most common cause of cancer deaths in men. ${ }^{1}$ Black men compared with White men have a 3-fold relative risk for PC. ${ }^{2}$ African-Caribbean men in the United Kingdom in comparison with other ethnicities have the highest incidence rate of $\mathrm{PC}^{3}$ The age-adjusted incidence rate for AfricanCaribbean men is 173 per 100000 in comparison with 56.4 per 100000 for White men. ${ }^{4}$ Furthermore, African-Caribbean men with a family history of PC are at higher risk. ${ }^{5}$ This represents a serious health inequality that needs investigating.

Knowledge and awareness of PC increase the likelihood of attendance at general practitioner surgeries for screening. ${ }^{6}$ However, a recent UK study found that while Black and White men had similar levels of knowledge about PC risks, $20 \%$ of White men had been tested for PC in comparison with only $5 \%$ of Black men. ${ }^{7}$ Therefore, it is likely that mortality rates are also a consequence of psychosocial aspects related to screening and presentation. ${ }^{8}$ Evidence collated from studies investigating the perceptions of PC in African-Caribbean men revealed that treatments for PC and trust/mistrust of health care services are likely to impact greatly on early/late presentation with the disease. ${ }^{9}$

Other research indicates that the digital rectal examination (DRE) is a significant barrier for some men. For example, in an American survey of 13580 men undergoing prostate-specific antigen, only $78 \%$ indicated that they would be willing to also undertake DRE testing. ${ }^{10}$ Similarly, lower levels of DRE screening were found in younger African-American, Haitian, Pueto Rican, and Eastern European men in comparison with White men. ${ }^{11}$ It is likely that fear is a factor in the low uptake in DRE screening; thus, lowering the fear levels would improve screening frequency. ${ }^{11} \mathrm{~A}$ further American study of 533 men 
supported this difference, finding that African-American, Jamaican, and Trinidadian/Tobagonian men undergo DRE less often, were more concerned about PC, and had higher screening fear scores than US born White men. ${ }^{12}$

Only a few qualitative pieces of research have attempted to explore barriers to screening uptake. One American-based study ${ }^{13}$ employed 4 focus groups to examine African-American men's prostate screening behavior. Men held a number of negative views surrounding screening: emotional stress about tests, decreased quality of life, humiliation and feeling violated by DRE, and the potential impact on their sex life. A further qualitative study of African-American men ${ }^{14}$ conducted 4 focus groups with healthy men, 2 focus groups with PC survivors, and 14 interviews with key community informants. Participants raised issues about inadequate access to health services (due to lack of insurance), mistrust of the health system, and poor relationships or communication between patients and medical providers. Other issues that impacted on health behavior were pride in maintaining their own health, and perceived threats to sexuality, both acting as major barriers to screening and also to receiving prostate care.

In the United Kingdom a qualitative study of 16 first generation African-Caribbean men ( $n=15$ from Jamaica) considered their experiences of the disease and participants' perceptions of the services they received. Barriers to earlier presentation included a fear of cancer and, again, of DRE. ${ }^{15}$ A further UK study with 7 African and AfricanCaribbean men found that men feared PC and its effect on relationships in terms of developing erectile dysfunction. Two participants spoke up about fears of testing saying that, while intrusive, it was a "necessary evil."16

The above studies have made some progress in outlining the reasons why Black men may delay seeking help when they are ill. Fears surrounding the DRE appear salient across both quantitative and qualitative studies in samples from the United States and the United Kingdom. However, these studies present a limited focus on this particular issue. DRE was identified as a key barrier in the current qualitative study, and thus, it is explored in more detail in this paper. Furthermore, the study focuses on African-Caribbean men in the United Kingdom in light of the limited research from men in this vicinity. A discursive approach is employed in order to consider the ways in which African-Caribbean men situate themselves within wider discourses.

\section{2 | METHODS}

The findings from this study represent 1 analytic aspect of a research project that aimed to contribute to a better understanding of the poor prognostic outcomes for PC in UK African-Caribbean men, with the end goal of producing a health promotion mobile application.

\section{1 | Participants}

The wider study was designed to incorporate both African-Caribbean men with PC $(n=10)$ and without cancer $(n=10)$ to gain an understanding of the barriers for those directly affected but also those who might be affected in the future. The study explored men's knowledge and understanding about PC, the barriers to screening, and their experience and treatment of PC where relevant. The 2 sets of participants were not treated as comparison groups; rather, their input on issues was treated as equally valid to the goals of the wider study and to the current study. Opportunist recruitment of participants to the study was conducted by members of the African-Caribbean community (BME Cancer Communities and a PC support group) who were included in every aspect of the research process. The advantage to this type of recruitment was that the White middle-class interviewer was able to contact "hard to reach," or "seldom heard," voices of African-Caribbean men.

\section{2 | Procedure}

The project received ethical clearance via the relevant University ethics committee; invitations were sent out to African-Caribbean men with and without PC. Details of who took part in the study are as follows:

Participant Details

\begin{tabular}{lcc}
\multicolumn{3}{l}{ Men without prostate cancer } \\
\hline Pseudonym & \multicolumn{1}{l}{ Country of origin } & Age at interview (years) \\
\hline Gregory & England (Jamaican parents) & 53 \\
Leroy & Jamaica & 58 \\
Don & Jamaica & 79 \\
Herbert & Jamaica & 73 \\
Jermain & Jamaica & 63 \\
Derek & Jamaica & 68 \\
Clement & Jamaica & 63 \\
Jordan & Jamaica & 79 \\
Delroy & England (Jamaican parents) & 35 \\
Sean & England (Jamaican parents) & 30
\end{tabular}

\begin{tabular}{|c|c|c|c|c|}
\hline \multicolumn{5}{|c|}{ Men with prostate cancer } \\
\hline Pseudonym & $\begin{array}{c}\text { Country of } \\
\text { Origin }\end{array}$ & $\begin{array}{c}\text { Age at } \\
\text { interview } \\
\text { (years) }\end{array}$ & $\begin{array}{c}\text { Age } \\
\text { diagnosed } \\
\text { (years) }\end{array}$ & Treatment \\
\hline George & Jamaica & 83 & 82 & $\begin{array}{l}\text { Radical } \\
\text { prostatectomy }\end{array}$ \\
\hline Joel & Jamaica & 63 & 57 & $\begin{array}{l}\text { Radical } \\
\text { prostatectomy }\end{array}$ \\
\hline Alex & Jamaica & 65 & 62 & $\begin{array}{l}\text { Hormone } \\
\text { therapy }\end{array}$ \\
\hline Jack & Trinidad & 68 & 61 & $\begin{array}{l}\text { Radical } \\
\text { prostatectomy }\end{array}$ \\
\hline Sam & Jamaica & 60 & 53 & $\begin{array}{l}\text { Radical } \\
\text { prostatectomy }\end{array}$ \\
\hline Glenmore & Jamaica & 79 & 59 & $\begin{array}{l}\text { Radical } \\
\text { prostatectomy }\end{array}$ \\
\hline Cleave & Jamaica & 77 & 74 & $\begin{array}{l}\text { Hormone } \\
\text { therapy }\end{array}$ \\
\hline Dwayne & $\begin{array}{l}\text { England } \\
\text { (Jamaican } \\
\text { parents) }\end{array}$ & 59 & 56 & $\begin{array}{l}\text { Radical } \\
\text { prostatectomy }\end{array}$ \\
\hline Paul & Jamaica & 61 & 57 & $\begin{array}{l}\text { Watchful } \\
\text { waiting }\end{array}$ \\
\hline Calvin & Saint Kitts & 72 & 67 & $\begin{array}{l}\text { Radical } \\
\text { prostatectomy }\end{array}$ \\
\hline
\end{tabular}


Semistructured interviews were conducted and transcribed using a Jefferson style transcription method (see appendix for details) in order to capture the nuances of the interaction. The data files were shared with a member of BME Cancer Communities in order to allow a transparent process with the community.

A synthetic discursive approach ${ }^{19}$ was used to analyze the data as they are best suited to exploring both broader and local orientations. The first stage of analysis involved mapping out any interpretive repertoires ${ }^{17-19}$; these are recognizable arguments,

\section{1 | Interpretative repertoire: homophobia and the digital rectal examination}

Across the interviews it became apparent that there was a taken-forgranted understanding that DRE was a key barrier to help-seeking. This section outlines an interpretative repertoire about these fears stemming from homophobia. The first extract highlights this knowledge in a covert manner, which places more emphasis on the interviewer pursuing further explanation.

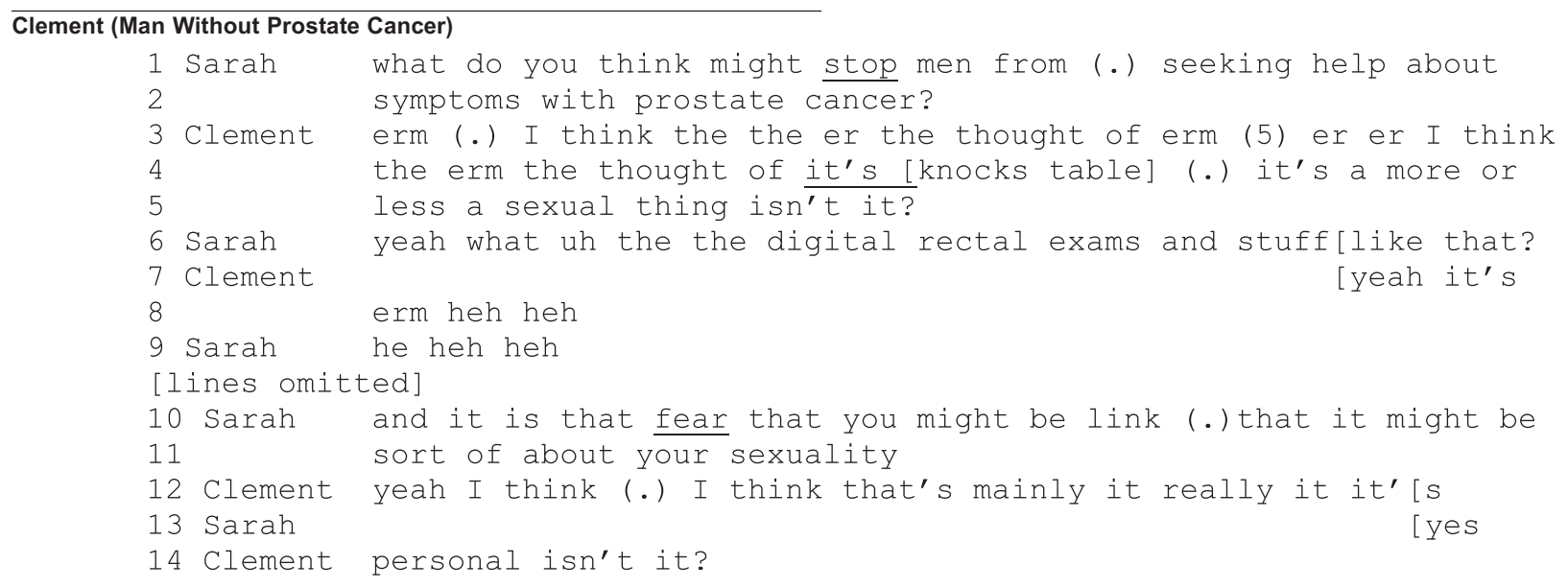

descriptions, and evaluations found in people's talk. Interpretative repertoires are "what everyone knows." Indeed, the collectively shared social consensus behind an interpretative repertoire is often so established and familiar that only a fragment of the argumentative chain needs to be formulated in talk to form an adequate basis for the participants to jointly recognize the version of the world that is developing. Typically, interpretative repertoires also set up "subject positions." Story lines provide us with a position to speak from, and they allow the positioning of others as characters with roles and rights. Of particular relevance is the insight that "one speaker can position others by adopting a story line which incorporates a particular interpretation of cultural stereotypes to which they are 'invited' to conform," ${ }^{20}$ (p 54). Thus, the second analytic stage involved paying attention to the positions afforded within the interaction. Insights from conversation analysis concerning the sequential unfolding of talk $^{21}$ are also considered in order to ground observations in the details of the interaction.

The use of interviews is critiqued within discursive psychology. ${ }^{22,23}$ Therefore, during the analysis the interviewer is treated as a coparticipant and attention is paid to the way that her contributions impact on the interaction. The analysis that follows is necessarily restricted to observations relevant to the argument developed due to space restrictions.

\section{3 | RESULTS}

The first analytic section focuses on the orientation to an interpretative repertoire of homophobia linked to the DRE.
Clement constructs a barrier as being "more or less a sexual thing." However, this is ambiguous and produced in a way that is hedged (note the repetition of "I think," the long silence, and the tag question "isn't it?"). As a consequence, after an initial positive receipt, the interviewer pursues further explanations via 2 candidate answers ${ }^{24}$ : firstly making a link to the DRE (lines 6) and then to sexuality (lines 10 and 11). Offering a candidate an answer is useful when the cointeractant appears to be having difficulty giving a satisfactory answer without a model. ${ }^{25}$ However, the interviewer also orientates to Clement's epistemic knowledge ${ }^{26}$ in the way she hedges these constructions (displayed via the questioning intonation in line 6, and the repaired formulation in line 10 , and with the hedging "it might be sort of" in lines 10 and 11).

This repertoire is oriented more overtly in the next 2 extracts. However, it should be noted that these interactions are co-constructed with Sarah (who arguably has more power as the interviewer), offering her own formulations at times. For example, the way that Sarah designs her turn in line 1 of extract 2 (albeit with the insertion of "probably") makes it hard for Delroy to disagree. Similarly, prior to extract 3, Alex constructed macho pride as being a barrier to men seeking help, which led to a discussion about the DRE and homosexuality.

In extract 2, Delroy accepts the interviewer's account and upgrades it to being "the crux" of the matter but hedges this with "probably." While Delroy constructs DRE as being problematic for "most men," he marks out the "Afro-Caribbean community" as being more troubled by links to homosexuality. Delroy speculates with the use of a 3-part list $^{27}$ that African-Caribbean men are socialized to believing that their anal passage should not be "touched" or "probed" or "anything like that." Similarly, Alex (extract 3) constructs a link 


\section{Delroy (Man Without Prostate Cancer)}

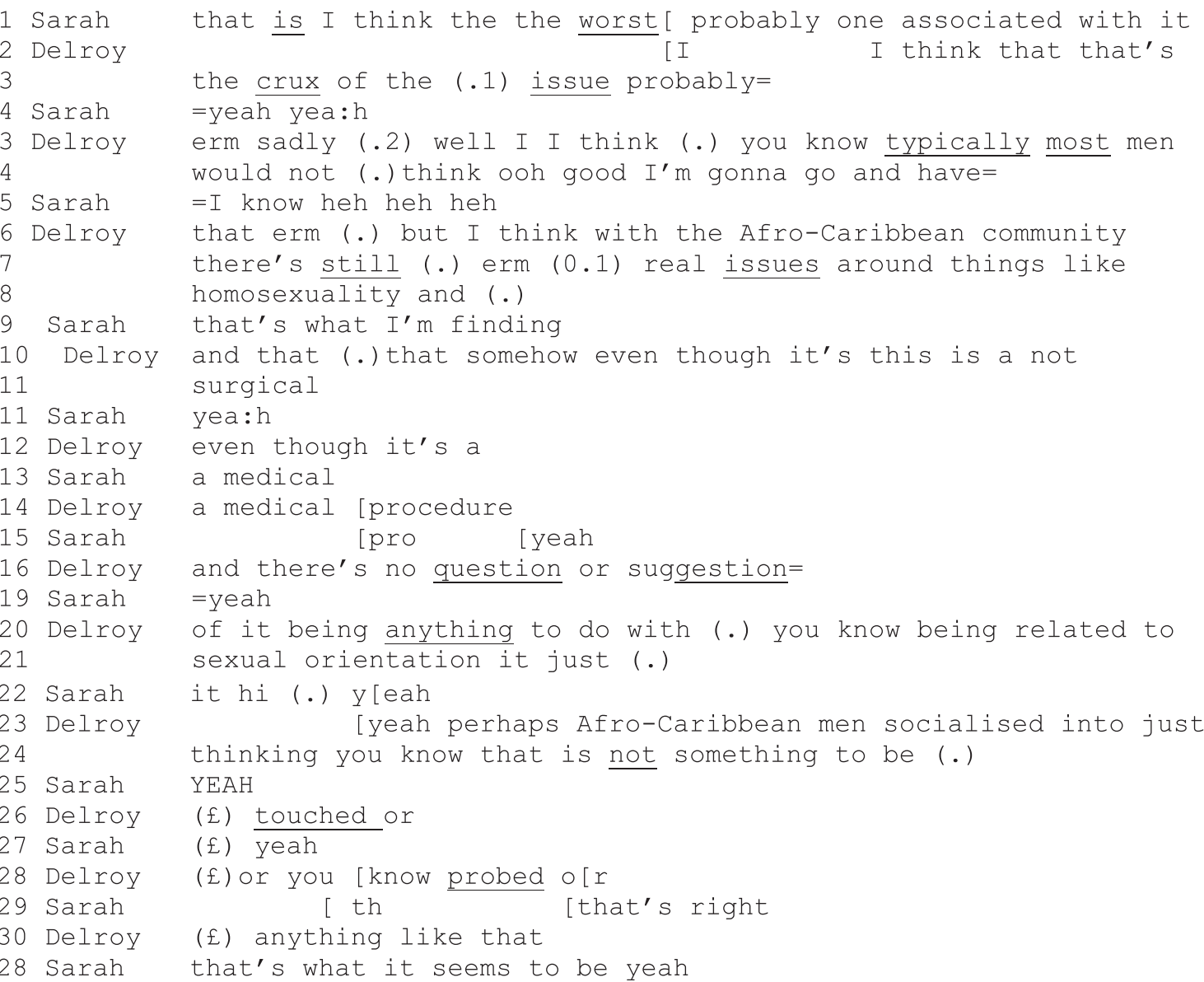

Alex (Man With Prostate Cancer)

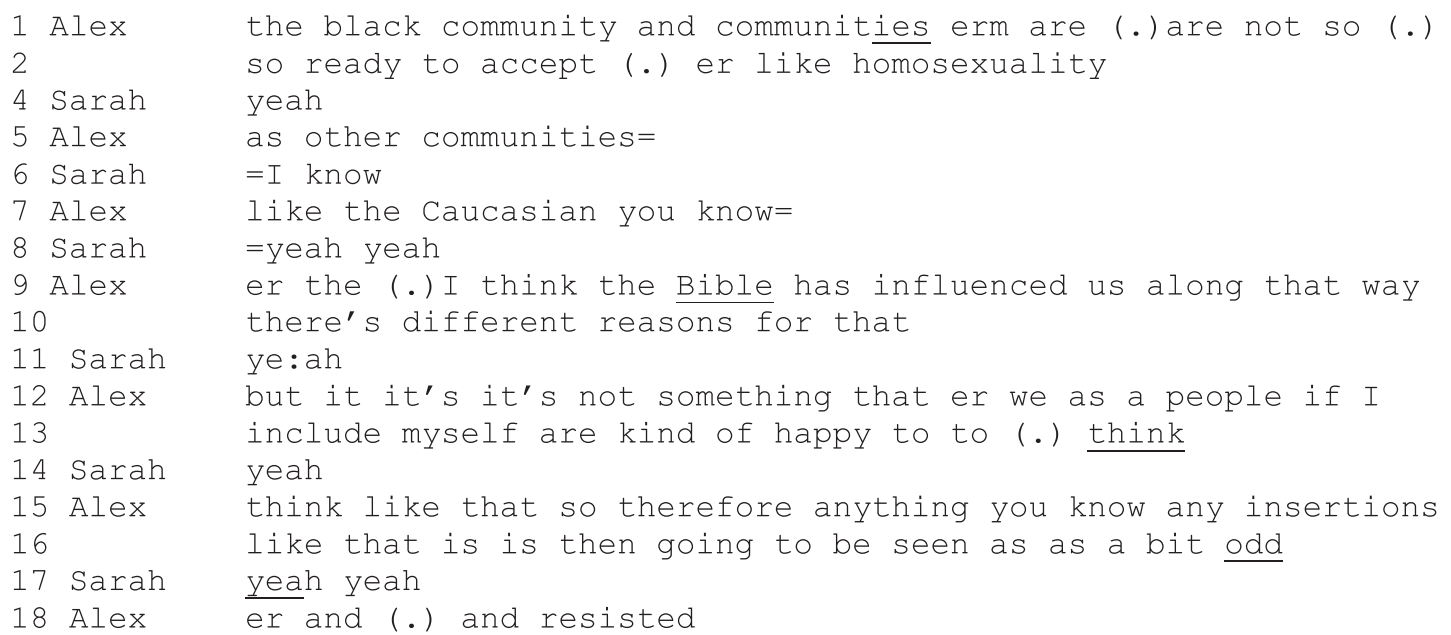

between black communities' reluctance to accept homosexuality to the DRE via a discussion of "insertions" being viewed as "a bit odd ... and resisted."

Sarah displays her alignment and epistemic knowledge to the unfolding discussion regarding the repertoire (eg, extract 2, lines 5, 9, and 28; extract 3, line 6). Despite this, orientations to the socially delicate management of such a topic ${ }^{28}$ are displayed via the laughter (extract 2, line 5) and smiley voices (extract 2, lines 26-30) during these constructions.

\subsection{Positioning and accountability}

This section considers how participants position and account for their actions in relation to the interpretative repertoire identified above.

Derek constructs Caribbean men, particularly Jamaican and the older generation, as prone to not wanting the DRE. The shared laughter at lines 1 and 2 is due to Derek's Jamaican origins, which is supported by the switch in footing ${ }^{29}$ from men to "we" in line 3. Derek thus switches footing at a point that places him within this framework 


\section{Derek (Man Without Prostate Cancer)}

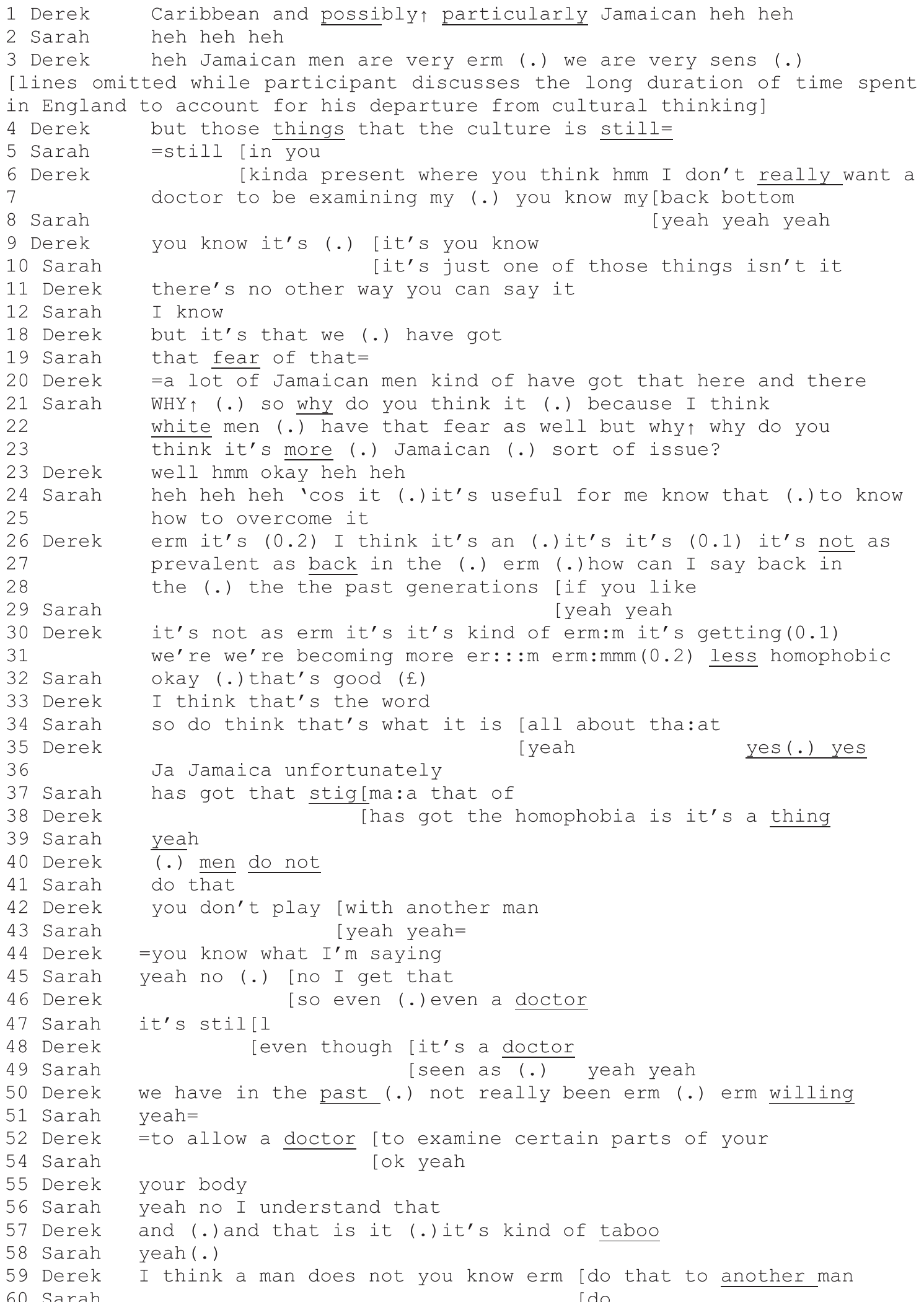

of thinking. However, Sarah's completion of his turn at line 5 is qualified with Derek's "kinda present." Derek's footing moves to a more generic footing of "you think" before using active voicing to orient to the repertoire (lines 6 and 7). Sarah orients to fear regarding the DRE (line 19). However, Derek's positive receipt is noticeably latched to
Sarah's construction, displaying an alignment (though note the hedged "kind of" and "here and there"). When pressed by the interviewer to explain this further, Derek makes links to homophobia, with Jamaican men viewing contact "in certain parts of your body" as "taboo." Again, in line 31, Derek switches footing to "we" to construct Caribbean men 
as "less homophobic," then later to "Jamaica" (line 36), "men" (line 40), and "you" (line 42).

One problem inherent in research interviews that links to this discussion of footing is whether participants are speaking as an individual or as a category member. ${ }^{22}$ The difficulty for Derek is that the tasks set by the interviewer incorporate both of these positions. Sarah asks Derek to provide an explanation of the phenomena as an individual, "why do you think" (line 21) and as a category member of the Jamaican community (line 23), making him accountable on both fronts. Furthermore, Derek's identity is also at stake here ${ }^{30,31}$-if he positions himself as part of this problem, then his identity is "troubled." ${ }^{19}$ The interviewer's footing is also tricky-Sarah's style of interviewing is not neutral, and her footing and co-constructions demonstrate this. Part of this is arguably about developing a rapport and managing these socially delicate discussions.

Footing is also relevant to the way men with PC manage their identities-how do they account for "breaking" this barrier?

\section{4 | CONCLUSIONS}

An interpretative repertoire of cultural homophobic beliefs permeates the way that DRE is viewed as a potential stigma, which in turn is constructed as a barrier to diagnosis. The taken-for-granted way that this issue is oriented to by the participants (including the interviewer) displays the power that it holds over these men. However, the discursive approach taken in this paper also demonstrates the way that participants negotiated their position within this repertoire, highlighting an understanding that such behavior was damaging to their health and needed to be addressed within the community. Attention to footing and accountability also demonstrate how 2 of the men with PC constructed a pragmatic position for themselves. To overcome any potential stigma associated with transgressing cultural norms associated with DRE, the men typically invoked the voices of general practitioners who sanctioned their behavior, potentially alleviating any criticism of their masculine African-Caribbean identity.

Jack (Man With Prostate Cancer)

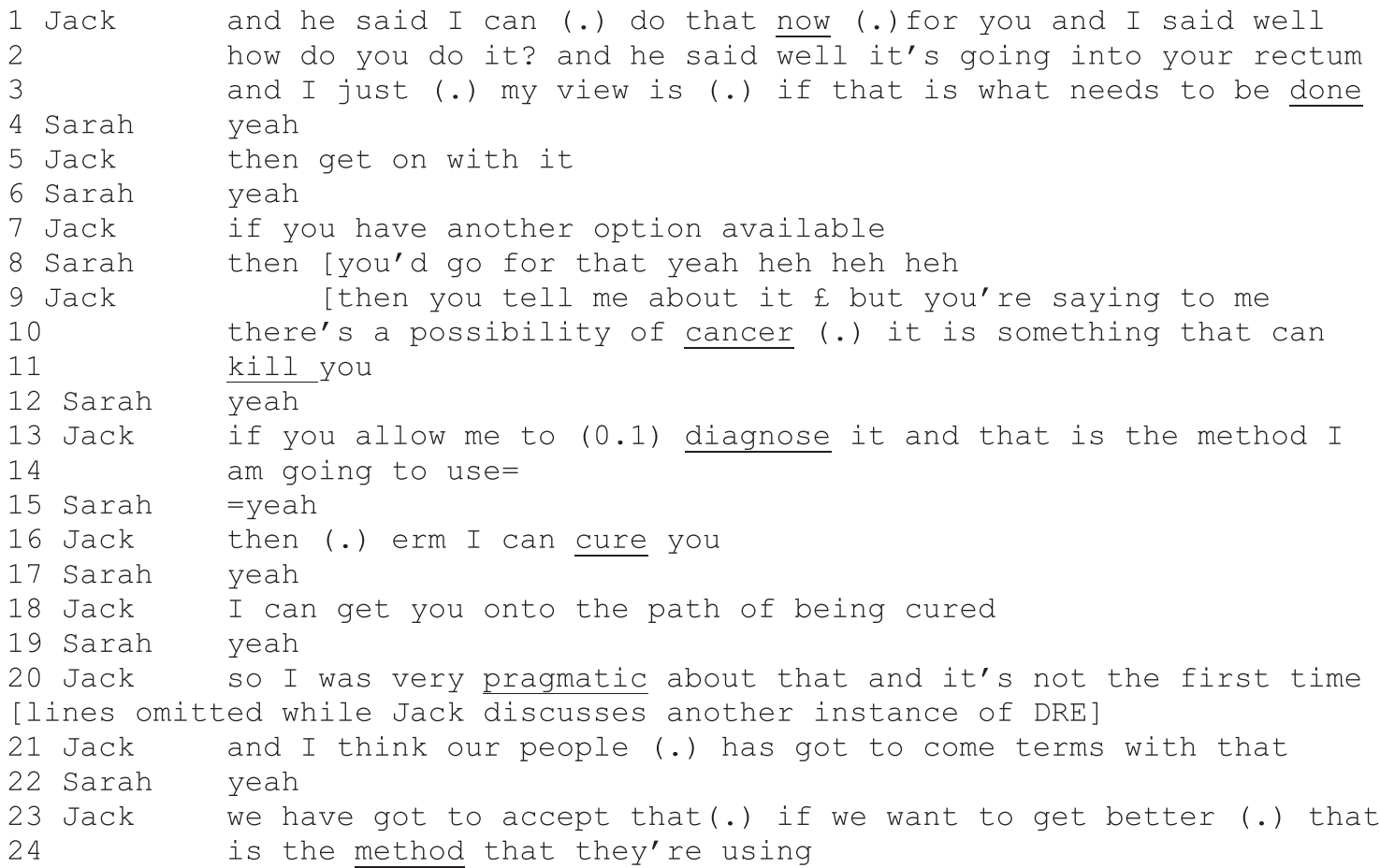

Both Jack and Joel formulate conversations that they had with their doctor. Invoking their doctor is possibly a means of protecting their African-Caribbean masculine identities-the reference to bottom-line arguments around death (extract 5, lines 16-18; extract 6, lines 23-24) protects their identities as men who have had the DRE. Indeed, studies of men's health highlight how hegemonic masculinity can impact negatively on men's health behavior in that they are supposed to act stoically, thus seeking help is not viewed as "manly." ${ }^{\text {"3,34 }}$ Research has also argued that protecting men's masculine identity is a key issue in overcoming barriers to health care. ${ }^{35,36}$ Both Jack and Joel digress from the cultural associations with DRE that are problematic and manage a position for themselves as pragmatic through reference to medical authority and potential death.
The implications of the study are that health promotion interventions targeting this health inequality need to address the fear of homophobia in this population. No discussion about the sex of the doctor was sought; however, it may be that the offer of a female doctor could lessen fears about homophobia. Researchers have stressed the need for the development and evaluation of carefully designed interventions, which will allow Black and Minority Ethnic groups to make informed decision making about PC. ${ }^{12}$ BME Cancer Communities with their advice and the PC support group who were part of the advisory panel for this research, and the men in this study, argued that the best approach to overcoming fears associated with DRE were by talking openly and sympathetically about the issue with the aid of members of the community. Therefore, the research team utilized findings from 
Joel (Man With Prostate Cancer)

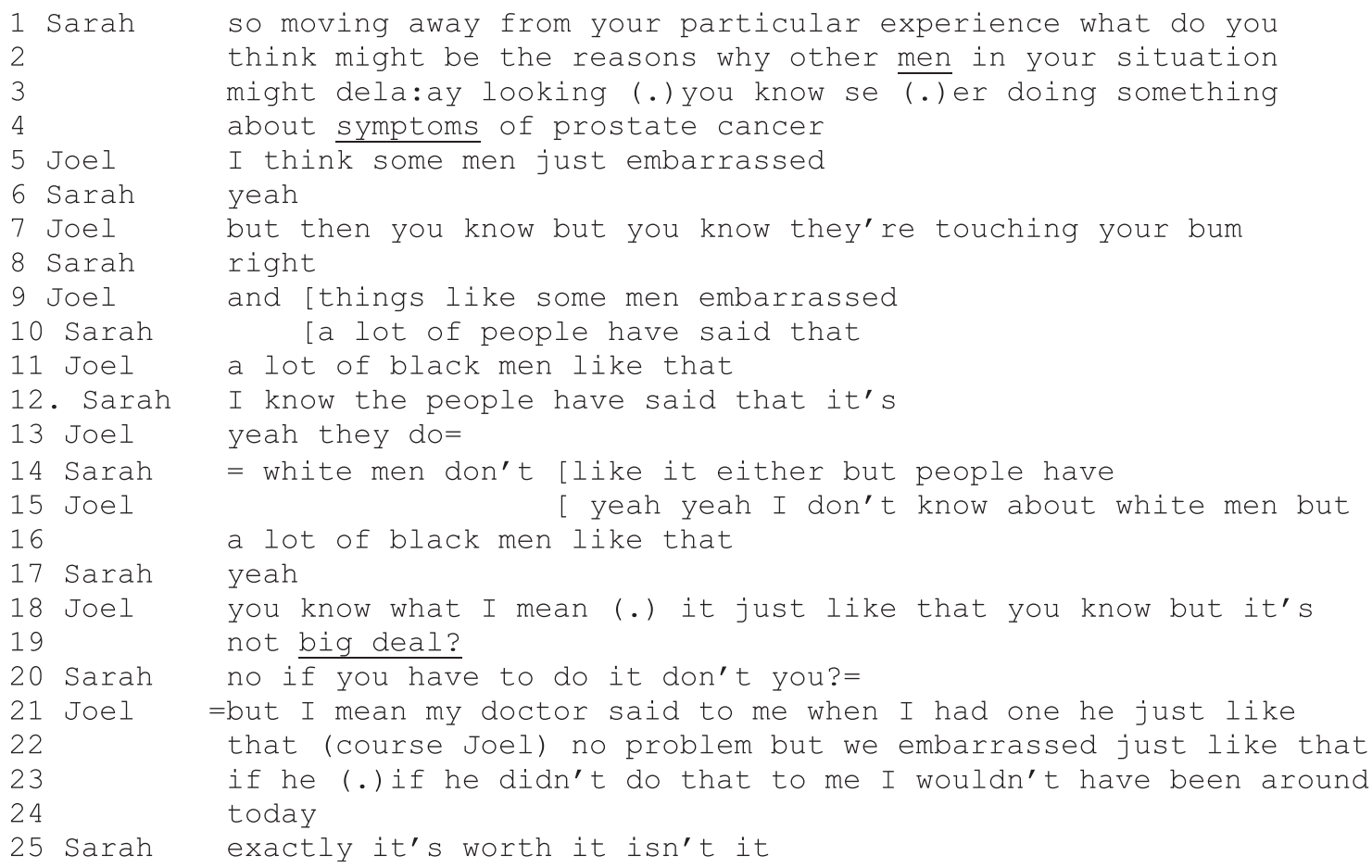

this, and the wider study, to produce a mobile application (PROCEE) that was designed with key members of the community, including a local African-Caribbean actor who provided the voices, narrative, and characters within the app. The application provides PC information and evaluates risk based on embedded expert rules for reasoning with symptom data entered by users. During focus group evaluations, users emphasized that it can potentially have a positive impact on changing user behavior among high-risk men who are experiencing symptoms and who are reluctant to visit the doctor. ${ }^{32}$ The majority of men in this study constructed DRE as a barrier; however, a limitation of the study is that the views of the men may not be representative of all African-Caribbean men. The participants were an opportunity sample and were all of Jamaican origin with the exception of a man from Saint Kitts and a further from Trinidad. Future research and health promotion regarding PC and African-Caribbean men should continue, designing information at an even younger age group in order to dispel any cultural barriers.

\section{ACKNOWLEDGEMENTS}

The authors would like to thank Rose Thompson (Black and Ethnic Minority Ethnic [BME] Cancer Communities), the Prostate Cancer Support Group, Professor Graham Pockley, and Ms Sue Dewey in the John van Geest Cancer Research Centre and all the participants in the study. The research was funded by NHS Nottingham City Clinical Commissioning Group's Allocation of National Institute for Health Research (NIHR) Research Capability Funding (contract number: CCG/NTU/02/RCF/13-14). Toward a Better Understanding of the Poor Prognostic Outcomes for Prostate Cancer in the AfricanCaribbean Community.

\section{REFERENCES}

1. Cancer Research U.K., Prostate cancer, incidence statistics, 2012

2. Chinegwundoh F, Enver M, Lee A, Nargund V, Oliver T, Ben-Shlomo Y. Risk and presenting features of prostate cancer amongst AfricanCaribbean, South Asian and European men in North-east London. BJU Int. 2006;98:1216-1220.

3. Thompson R. BME Cancer Communities. Hear me now.

4. Parliamentary Stakeholder Group Chaired by Paul Uppal MP. Prostate cancer in BME communities: raising awareness and improving outcomes.

5. Ben-Shlomo Y, Evans S, Ibrahim F, et al. The risk of prostate cancer amongst Black men in the United Kingdom: the PROCESS Cohort Study. Eur Urol. 2008;53:99-105.

6. Salami MA, Etukakpan B, Olapade-Olaopa EO. Update on prostate cancer in black men. JMHG. 2007;4(4):456-463.

7. Rajbabu K, Chandtaskera S, Zhu G, et al. Racial origin is associated with poor awareness of prostate cancer in UK men, but can be increased by simple information. Prostate Cancer Prostatic Dis. 2007;10(3):256-260.

8. Pederson VH, Armes J, Ream E. Perceptions of prostate cancer in Black African and Black Caribbean men: a systematic review of the literature. Psychooncology. 2011;21:457-468.

9. Ream E, Pedersen A, Armes J. Perceptions of prostate cancer and prostate cancer risk in men of African Caribbean descent: a systematic review. Eur J Oncol Nurs. 2010;14(1):142-151.

10. Nagler HM, Gerber EW, Homel P, et al. Digital rectal examination is barrier to population-based screening. Urology. 2005;12:1137-1140.

11. Consedine NS, Morgenstern AH, Kudadjie-Gyamfi E, Magai C, Neugut Al. Prostate cancer screening behaviour in men from seven ethnic groups: the fear factor. Cancer Epidemiol Biomarkers Prev. 2006;15:228-237.

12. Lee DL, Consedine NS, Spencer BA. Barriers and facilitators to digital rectal examination screening among African-American and AfricanCaribbean men. Urology. 2011;77(4):891-898. 
13. Odedina F, Scrivens J, Emanual A, LaRose-Pierre M, Brown J, Nash R. A focus group study of factors influencing African-American men's prostate cancer screening behaviour. J Natl Med Assoc. 2013;96 (6):780-785.

14. Allen JD, Kennedy M, Wilson-Glover A, Gilligan TD. African-American men's perceptions about prostate cancer: implications for designing educational interventions. Soc Sci Med. 2007;64:2189-2200.

15. Nanton V, Dale J. "It don't make sense to worry too much": the experience of prostate cancer in African-Caribbean men in the UK. Eur J Cancer Care. 2010;20:62-71.

16. Anderson B, Marshall-Lucette S, Webb P. African and Afro-Caribean men's experiences of prostate cancer. Br J Nurs. 2013;22(22):12961307.

17. Edley N. Analysing masculinity: interpretatative repertoires, subject positions and ideological dilemmas. In: Wetherell M, Taylor S, Yates SJ, eds. Discourse as Data: A Guide to Analysis. London: Sage and the Open University; 2001:189-228.

18. Potter J, Wetherell M. Discourse and Social Psychology: Beyond Attitudes and Behaviour. London: SAGE; 1987.

19. Wetherell M. Positioning and interpretative repertoires. Conversation analysis and post-structuralism in dialogue. Discours Soc. 1998;9 (3):387-412.

20. Davies B, Harre R. Positioning: the discursive production of selves. Theor Soc Behav. 1990;20(1):43-63.

21. Schegloff EA. Sequence Organization in Interaction: A Primer in Conversation Analysis. Cambridge: Cambridge University Press; 2007.

22. Potter J, Hepburn A. Discursive psychology as a qualitative approach for analysing interaction in medical settings. Med Educ. 2005;39 (3):338-344.

23. Seymour-Smith S. Applying discursive approaches to health psychology. Health Psychol (special issue on qualitative methods). 2015;34 (4):371-380.

24. Pomerantz A. Offering a candidate answer: as information seeking strategy. Communicat Monogr. 2009;55(4):360-373.

25. Jefferson G. A technique for inviting laughter and its subsequent acceptance/declination. In: Psathas G, ed. Everyday Language: Studies in Ethnomethodology. New York: Irvington Press; 1979:79-96.

26. Heritage J. The epistemic engine: sequence organization and territories of knowledge. Res Language Soc Inter. 2012;45(1):30-52.

27. Jefferson G. List construction as a task and resource. In: Psathas G, ed. Interaction Competence. Washington D.C.: University Press of America; 1990.

28. Silverman, D. Discourse of Counselling. HIV Counselling as Discursive Practice. London: SAGE; 1996.

29. Goffman E. Forms of Talk. Philadelphia, PA: University of Pennsylvania Press; 1981.

30. Edwards D, Potter J. Discursive Psychology. London: Sage; 1992.

31. Potter J. Representing Reality: Discourse Rhetoric and Social Construction. London: Sage; 1996.

32. Cosma G, Brown D, Shopland N, et al. PROCEE: A PROstate Cancer Evaluation and Education serious game for African Caribbean men. Journal of Assistive Technologies.

33. Courtenay W. Constructions of masculinity and their influence on men's well-being: a theory of gender and health. Social Science \& Medicine. 2000;50:1385-1401.

34. Seymour-Smith S, Wetherell M, Phoenix A. "My wife ordered me to come!": a discursive analysis of doctors' and nurses' accounts of men's use of general practitioners. Journal of Health Psychology. 2002;7 (3):253-267.

35. Gough B. 'Try to be healthy, but don't forgo your masculinity: deconstructing men's health discourse in the media'. Social Science \& Medicine. 2006;63:2476-2488
36. Seymour-Smith S. "Blokes don't like that sort of thing": Men's negotiation of a 'troubled' self-help group identity. J Health Psychol. 2008;13:798-803.

How to cite this article: Seymour-Smith, S., Brown, D., Cosma, G., Shopland, N., Battersby, S., and Burton, A. (2016), "Our People Has Got to Come to Terms With That": Changing Perceptions of the Digital Rectal Examination as a Barrier to Prostate Cancer Diagnosis in African-Caribbean men, PsychoOncology, doi: 10.1002/pon.4219

\section{APPENDIX \\ Transcription notation}

The form of notation used in the thesis is a simplified version of the transcription notation developed by Gail Jefferson.

- Extended square brackets mark overlap between utterances, eg,

A: [men overlapping utterances

B: [yeah

- An equal sign at the end of a speaker's utterance and at the start of the next utterance indicates the absence of a discernable gap, eg,
A: like I said before=
$\mathrm{B}$ : =when you mentioned

- Numbers in brackets indicate pause times to the nearest second. A full stop in brackets indicates a pause that is noticeable but too short to measure, eg,

A: he meant (2) that he felt (.) ill

- One or more colons indicate an extension of the proceeding vowel sound, eg,

B: I was very anxious:s about it

- Underlining indicates that words are uttered with added emphasis, and words in capitals are uttered louder than the surrounding text, eg,

A: I sent him to see a doctor but he WOULD NOT go

- Laughing is indicated by the word "heh heh," eg,

B: I can't say why heh heh

- A question mark is used to indicate rising intonation, often when there is a question, eg,

A: what did he say that for?

- $€$ is used to represent a smiley voice. 